The work is clearly a major contribution to our knowledge of the post-Palæozoic madreporarian corals, and will cause some hard thinking on the value in systematic classification of the microscopic structures of their hard parts.

H. Drghton Thomas

\section{PHOTOPERIODIC PHENOMENA}

Photoperiodism and Related Phenomena in Plants and Animals

Edited by Robert B. Withrow. (Proceedings of the Conference on Photoperiodism, October 29-November 2, 1957, sponsored by the Committee on Photobiology of the National Academy of SciencesNational Research Council, and supported by the National Science Foundation.) (Publication No. 55.) Pp. xvii +903. (Washington, D.C.: American Association for the Advancement of Science ; London : Bailey Bros. and Swinfen, Ltd., 1959.) $133 s$.

T HIS is a record of the proceedings of a conference held in Tennessee in the autumn of 1957 . It comprises the texts of all the formal contributions together with a number of short papers, presumably corresponding to some of the major items of informal discussion, which the preface optimistically calls "ideas submitted in written form". It wanders over a very wide field, sometimes straying into paths remote from photoperiodism. This breadth of cover is indicated by the eleven sections, corresponding presumably to lecture sessions, embracing photochemical principles, the photocontrol of seed germination, of vegetative growth and of reproduction in flowering plants, rhythmical phenomena in plants and animals and photoperiodic phenomena in invertebrates, in vertebrates and also in bird-migration. The object of this symposium was to promote the flow of ideas between workers on photoperiodism in the plant and animal fields. This, the main function (one might even claim it to be the only function) of the conference, was no doubt achieved at the meeting during informal contacts following the papers. But the reader of this bulky volume, in his struggle through nearly nine hundred pages of text containing a great mass of data from highly specialized research, will not easily become conscious of this flow, even if he retains the interest to look for it.

I feel strongly that the mammoth congress, catering at one and the same time for authoritative appraisals of fields of study, interim surveys of research group activities and reports of the current research of individuals, is misconceived. The publication in full of such a 'pot pourri' is an even greater mistake. This is not to say that a comprehensive review of current work and ideas in photoperiodic phenomena is not needed. It is in fact long overdue, and is to some extent met by this volume. There are in it a great many review papers, providing authoritative and balanced statements on the major 'growing points' of this complex of subjects. But they are cluttered up, particularly in the plant section, with specialized research contributions, which could with advantage have been omitted, particularly in view of the fact that in the intervening two years since the conference was held some have already been published in well-known journals. Some surveys also, the titles of which promise well, are disappointing, giving the impression that they are the bare bones of lectures and their writers had been pressed for time.
As with most American publications, the price is very high, and therefore calls for comment. The book should obviously find its greatest use in the hands of young research workers in this field and of advanced undergraduates, who would undoubtedly obtain valuable insight and stimulation from the better review articles. But the price is well beyond their pockets ; even heads of university departments will no doubt have to balance carefully the virtues of this book against the more tangible advantages of the equally expensive encyclopædias which are now appearing and which cover this subject completely.

$$
\text { L. J. Audus }
$$

\section{RELIGION AND SOCIAL STRUCTURE}

Oedipus and Job in West African Religion

By Prof. Meyer Fortes. Pp. 81. (Cambridge : At the University Press, 1959.) 10s. 6d. net.

WHIS book is an expanded version of the Frazer Lecture for 1956. In it Prof. Fortes gives a very interesting interpretation of the religious ideas of the Tallensi, and other West African societies, in terms of the CEdipus and Job stories, and tries to show that these ideas are reflexions of the social structure.

The aspect of the CEdipus story used here is not that made familiar by Freud : instead, it is the idea that some people are born with an evil destiny, and are never properly accepted by society; this is not of their choosing and they can do nothing about it. The interpretation of Job is that he was being tested and disciplined by a just God; Job was saved not by good works, but by recognizing his error in placing himself on a level with God.

Prof. Fortes finds parallels to these stories in West African religion, and he gives a detailed account of the ideas of the Tallensi. A parallel to Edipus is found in their idea of good and evil predestiny : this makes sense for them of the fact that some people have persistent bad luck, fail to bear children, die of mysterious diseases, and so forth. It is believed that the ancestors are responsible, since each person is thought to be the ward of an ancestor. However, unlike the CEdipus story, it is possible to overcome an evil destiny by ritual offerings and service to the ancestors, and who Fortes sees as equivalent to Job's just God. One can be saved only by obedience and subservience to the ancestors.

A further part of the thesis of this book is that "the Tallensi have an ancestor cult because the social structure demands it" (p. 66). It is pointed out tha there are different possible religious interpretations of good and bad fortune-the Azande blame it on witchcraft operated by living people, for example. The ancestor cult is a symbolic representation of the parents, resulting from the close discipline, authority and affection of the parent-child relationship.

Two general comments may be made about the book. In the first place, while the parallels drawn with European stories are interesting, and to some extent convincing, it is not made clear how the exposition or explanation of African religion is assisted by making them. Secondly, for a rigorous demonstration of the thesis that these religious ideas are a product of the social structure, a cross-cultural study would be required showing that ancestor cults are regularly associated with a certain quality of parent-child relations. MichaEL ARGyLE 